\title{
Flame Spread over Thin Layers of Crude Oil Sludge
}

\author{
TAKUJI SUZUKI and NORIHITO KUDO \\ Department of Mechanical Engineering \\ Ibaraki University \\ Ibaraki, Japan
}

\author{
JUN'ICHI SATO and HIDEO OHTANI \\ Research Institute \\ Ishikawajima-Harima Heavy Industries, Co., Ltd. \\ Tokyo, Japan
}

\author{
TOSHISUKE HIRANO \\ Department of Reaction Chemistry \\ University of Tokyo \\ Tokyo, Japan
}

\section{ABSTRACT}

Flame spread over thin layers of crude oil sludge has been studied. Flame spread experiments were performed by using a tray of $12 \mathrm{~cm}$ wide, $60 \mathrm{~cm}$ long and variable depth, installed in a temperature control bath. The aspects of spreading flames, the movements of leading and trailing flame edges, and the temperature distributions near leading flame edges were examined for various sludge layer thicknesses. The mode of flame spread was found to change at a moment several minutes after the start of flame spread. At the first stage, the flame spread rate was observed to be almost constant, while at the second stage, it changed periodically. The former was about twice as large as the latter. Two different limiting thicknesses were revealed. One was the limiting thickness for the initiation of flame spread and the other was that for the continuance of flame spread. Based on these results, the mechanisms of flame spread were discussed. All the flame spread phenomena were shown to be consistently interpretable by assuming similar mechanisms of flame spread as indicated in our previous study.

\section{INTRODUCTION}

Serious damage has been occasionally caused by a crude oil sludge fire in a cargo bay of a crude oil tanker during its repair. Since the growth rate of such a fire depends on the process of flame spread over it, knowledge of flame spread must be indispensable for developing a reliable fire protection method and/or establishing reasonable regulations or standards concerning the procedure for repair of the crude oil tanker.

Crude oil sludge is mainly the deposit of crude oil accumulated during voyages and remaining in the cargo bay after washing, so that it is a multicomponent combustible of non-definite composition. Further, a pasty crude oil sludge increases its fluidity as approaching the leading edge of a spreading flame[1,2]. Although the mechanisms of flame spread over single component liquid or solid combustibles have been examined in a number of previous studies[3-9], very little knowledge is available on flame spread over multicomponent combustibles like crude oil sludge.

Thus, in our previous studies, basic characteristics of flame spread over crude oil sludge were explored and analyzed[1,2]. The effects of sludge composition and/or temperature on flame spread phenomena were examined and the flame spread mechanisms were discussed[1]. Further, an analysis 
of flame spread over multicomponent combustibles was performed and the results were compared to those of the experiments on flame spread over crude oil sludge[2]. Knowledge obtained throughout these studies would be useful to understand the flame spread phenomena and to develop a test method for classifying the hazard of crude oil sludge.

Obviously, no fire occurs if crude oll sludge is completely removed from the floors, walls, and ribs in the cargo bay to be repaired. However, the complete removal of crude oil. sludge is practically impossible and the grade of the procedure to remove crude oil sludge directly affects the cost. Therefore, suitable regulations or standards for it must be necessary.

To establish reasonable regulations or standards for the crude oil sludge removal, the information concerning the effect of sludge layer thickness on the flame spread phenomena must be needed. Therefore, in the present study, the flame spread phenomena over various thicknesses of crude oil sludge layers have been examined in detail.

\section{EXPERIMENTAL APPARATUS AND PROCEDURE}

A tray installed in a temperature control bath was used for the flame spread experiments(Fig. 1). The width and length of the tray were $12 \mathrm{~cm}$ and 60 cn, respectively, which were determined on the basis of the results of preliminary experiments. The width of $12 \mathrm{~cm}$ would be sufficient for neglecting the quenching effect of side walls of the tray on flame spread phenomena, and the length of $60 \mathrm{~cm}$ would be enough for observing typical variations of flame spread phenomena with time. The base plate of the tray was a brass plate and made to be movable so that the depth could be changed. The brim of the tray was set to be flush with a flat plate covering the temperature control bath.

The properties of crude oil sludge depend on the crude oil quality, cargo bey wall conditions, and washing procedure. It makes the properties to be non-definite. As discussed in our previous study[1], however, the flammability of sludge, of which hazard assessment is needed, must be in a certain range. The sludge used in the present study was similar to one of those examined in the previous study[1]. Its properties were examined by thermogravimetry(TG), differential thermal analysis(DTA), and derivative thermogravimetry(DTG) in the inert gas (Ar) atmosphere. The results are shown in Fig. 2. These properties are close to those of the

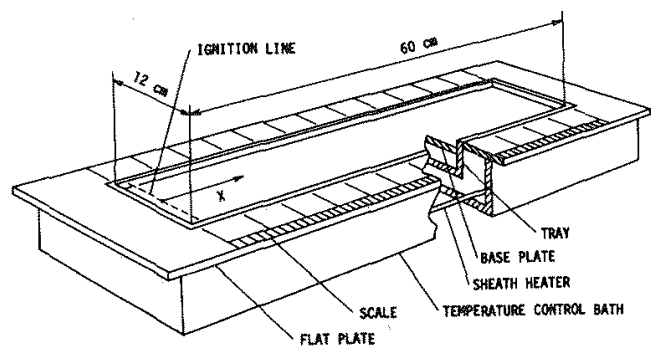

FIGURE 1. Tray and temperature control bath. sludge made by adding $10 \%$ hexane to the standard sludge, which was used in our previous study[1]. The horizontally placed tray was filled with the sludge and its surface was finished to be flat by using a trowe1. Then, a cotton string of $3 \mathrm{~mm}$ in diameter soaked with ethanol was laid on the sludge surface near the tray end brim to be parallel to it. The sludge was ignited by burning this cotton string. After igniting the sludge, the 


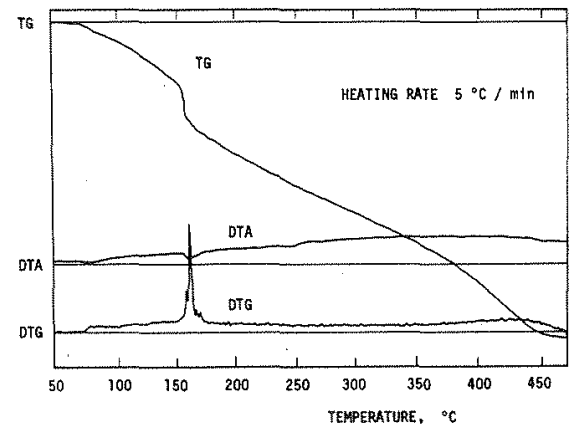

FIGURE 2. Properties of the sludge used in the present experiments, examined by thermogravimetry(TG), differential thermal analysis(DTA), and derivative thermogravinetry(DTG) in the inert gas(Ar) atmosphere.
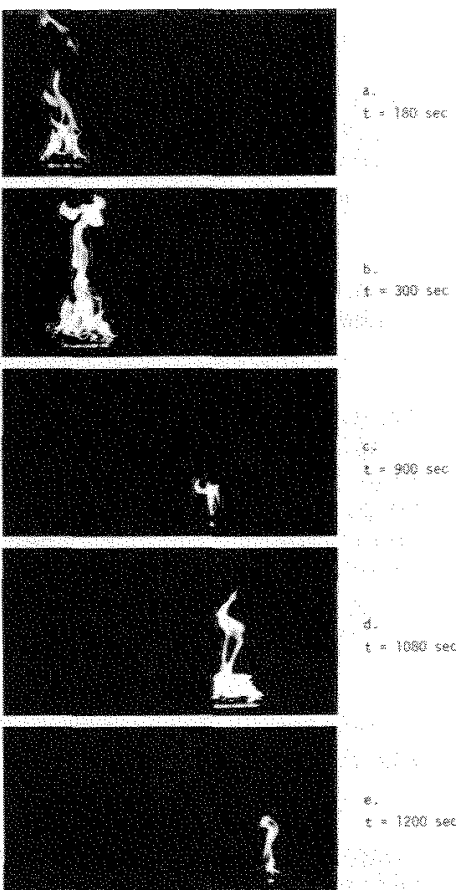

$\mathrm{E}=\operatorname{lan} \mathrm{s}$

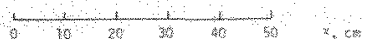

FIGURE 3. Processes of flame spread; $\mathrm{T}_{i}=20^{\circ} \mathrm{C}, \delta=0.3 \mathrm{~cm}$. string was taken off to eliminate its effect on flame spread phenomena.

The aspects of spreading flames were examined by using a motor-driven $35 \mathrm{~mm}$ camera, and the movements of the leading and trailing flame edges, which are described in the following secm tion, were measured by using a timer and the scale marked on the flat plate(Fig. 1).

The temperature distribution in the sludge during flame spread was measured by traversing a C-A thermocouple (wire diam.: $0.1 \mathrm{~mm}$ ) connected to a high speed digital recorder.

\section{RESULTS}

Aspects of Flame Spread

A series of photographs representing flame spread over a thin layer of the sludge is presented in Fig. 3. In this case, the initial sludge temperature $\mathrm{T}_{i}$ is $20^{\circ} \mathrm{C}$ and its thickness $\delta$ is $0.3 \mathrm{~cm}$. $t$ and $x$ in the figure represent the time after ignition and the distance from the ignition line, respectively. For a few minutes after the start of flame spread, the flame size is observed to increase( $a$ and $b$ in Fig. 3). Then, the flame edge at the end brim departs from it and trails the leading flame edge. The approach of the trailing flame edge to the leading flame edge causes the reduction of flame size(c). After the flame size becomes to be several $\mathrm{cm}$ in the longitudinal direction, it starts to increase again(d). Thus, a flame is observed to spread over the sludge repeating the enlargement and reduction of the flame size.

Just after a flame starts to spread, the melted sludge surface beneath the flame is observ" to be 


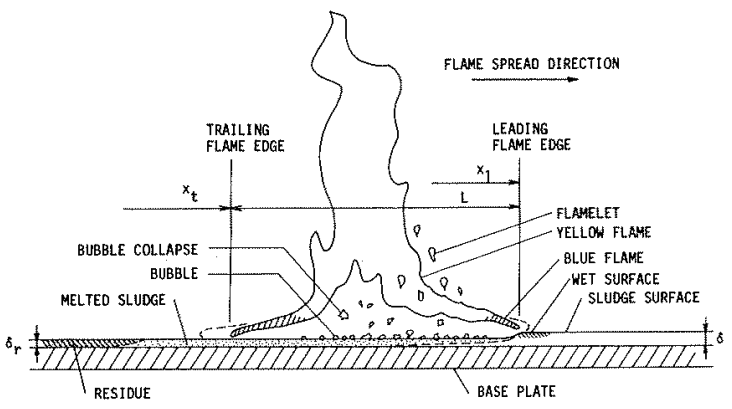

FIGURE 4. Schematic illustration of a spreading flame. slightly higher than the unburned sludge surface. During flame spread, the sludge beneath the flame is consumed, so that the melted surface becomes lower than the unburned sludge surface, and after several minutes, the trailing flame edge starts approaching to the leading flame edge.

A typical aspect of a flame spreading over a thin layer of the sludge is depicted

in Fig. 4. A blue leading flame is observed. The sludge melts just the liquid state beneath the flame.

edge followed by a luminous yellow zone behind the leading flame edge and it is in

A blue flame oscillates back and forward over a few cm in front of the melting boundary of the sludge. The sludge surface, over which the blue flame propagates, becomes wet. In the region behind the leading flame edge, boiling of the melted sludge is observed. When the flame size

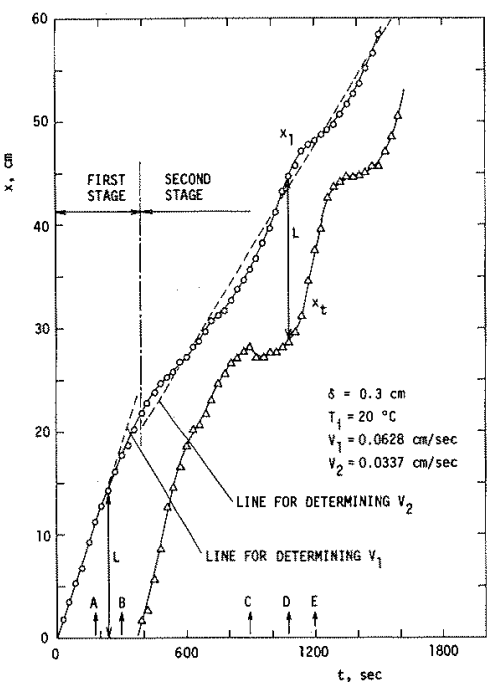

FIGURE 5. Position-time, $x-t$ diagrams representing the movements of leading and trailing flame edges for a typical case. is large, the boiling becomes intense and flamelets caused by the collapse of bubbles are observed over the main yel. low flame zone.

Behind the trailing flame edge, an oscillatory propagating blue flame is also observed. The amplitude and the period of oscillation are larger than those for the preceding blue flame. The residue behind the trailing flame edge hardens to be non-fluid.

Movements of Leading and Trailing Flame Edges

The position-time, $x-t$, diagrams representing the movements of leading and trailing flame edges for a typical case are shown in Fig. 5. $x_{I}$ and $x_{t}$ are the locations of the leading and trailing flame 


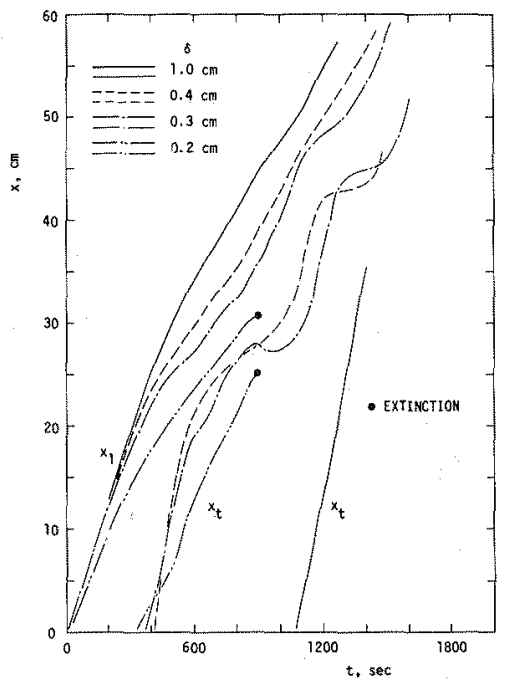

FIGURE 6. Position-time, x-t diagrams representing the movements of leading and trailing flame edges for various cases; $\mathrm{T}_{i}=20^{\circ} \mathrm{C}$.

The flame behavior for $\delta=1 \mathrm{~cm}$ is not much larger value of $\delta[1]$. edges, respectively(Fig. 4). Points A-E represent the times when the photographs in Fig.2 were taken.

At an earlier stage (the first stage) of flame spread, the leading flame edge is found to spread at a constant rate $V_{1}$. In the following stage (the second stage), it is seen that the instantaneous spread rates of the leading and trailing flame edges fluctuate periodically and that the mean spread rate $V_{2}$ of the leading flame edge is smaller than $\mathrm{V} \uparrow$.

The movements of the leading and trailing flame edges for various sludge thicknesses $\delta$ were examined and the results represented by $x-t$ diagrams are shown in Fig. 6. It can be seen that the characteristic of flame spread depends largely on $\delta$.

The period for the first stage decreases as $\delta$ decreases, and for $\delta=0.2 \mathrm{~cm}$, the flame stops spreading at about 15 minutes after the start of flame spread. so much different from that for a

The variation of the flame spread rate $V$ with time can be determined from an $x-t$ diagram. Figure 7 shows those obtained from the $x-t$ diagrams in Fig. 6. The flame spread rate at the first stage is found to be constant and its period for $\delta=1 \mathrm{~cm}$ is longer than that for $\delta=0.2$, 0.3 , and $0.4 \mathrm{~cm}$. No distinctive difference can be found between the variations of the flame spread rate at the second stage for values of $\delta$ from 0.3 to $1.0 \mathrm{~cm}$.

The values of $V_{1}$ and $V_{2}$ were examined for various cases. The results are shown in Fig. 8. $V_{1}$ for $\delta=0.4$ and 0.3 $\mathrm{cm}$ is found to be similar to that for $\delta=1 \mathrm{~cm}$, while $\mathrm{V}_{1}$ for $\delta$ $=0.2 \mathrm{~cm}$ is a little smaller than those for a larger value of $\delta$. Further, $V_{1}$ for $\delta=0.1 \mathrm{~cm}$ is zero, i.e., for $\delta=0.1 \mathrm{~cm}$ no

FIGURE 7. Variation of flame spread rate is zero, i.e., for does spread at the first $\mathrm{V}$ with time; $\mathrm{T}_{\mathrm{i}}=20^{\circ} \mathrm{C}$. 

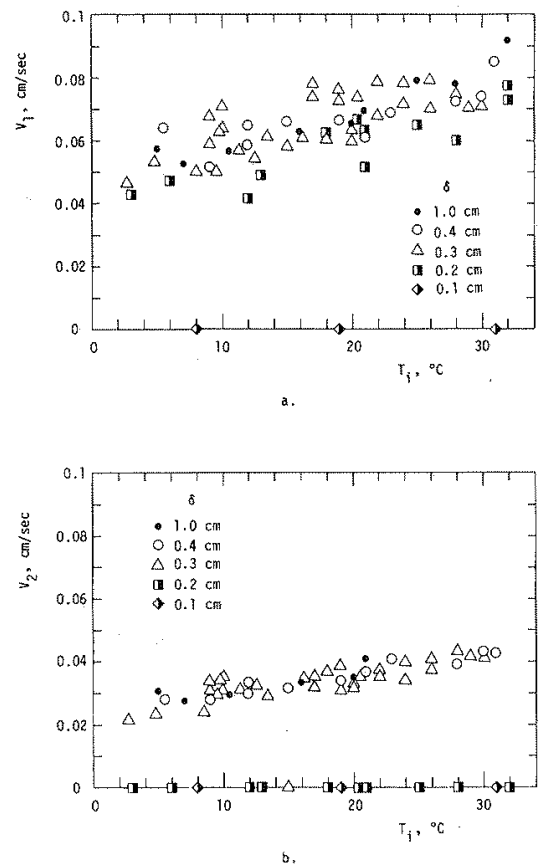

FIGURE 8. Flame spread rates $V_{1}$ at the first stage(a) and mean flame spread rates $V_{2}$ at the second stage $(b)$. stage. $V_{2}$ for $\delta=0.4$ and $0.3 \mathrm{~cm}$ is similar to that for $\delta=1 \mathrm{~cm}$. In this case, $V_{2}$ for $\delta=0.2 \mathrm{~cm}$ and $0.1 \mathrm{~cm}$ is zero, i.e., for $\delta=$ 0.2 and $0.1 \mathrm{~cm}$ no flame does spread at the second stage.

\section{Flame Size}

In the first stage, the trailing flame edge is staying at the tray end brim, so that the longitudinal flame size $I_{1}=x_{1}-x_{t}$, increases with time. In the second stage, the trailing flame edge moves oscillatory, and the variation of Lis caused by this behavior of the trailing flame edge.

L at an arbitrary moment can be determined from an $x-t$ diagram. The fluctuations of $\mathrm{L}$ were examined and are shown in Fig. 9. For $\delta=1 \mathrm{~cm}, L$ continues to increase until $t$ becomes more than 15 minutes. The period during which $L$ continues to increase decreases as $\delta$ decreases. For first several minutes, L continues to increase and then, it decreases. After L decreases to several cm, it starts to increase again. In the succeeding period, L changes periodicaliy.

\section{Temperature Distribution in Sludge Layer}

Figure 10 presents a typical temperature distribution in the sludge layer near the leading flame edge, which was measured at the moment when $x_{1}=10$ $\mathrm{cm}$ (in the first stage). The fluid-non-fluid boundary is assumed to be equal to the equi-temperature line for $\mathrm{T}=50^{\circ} \mathrm{C}$. In the region within a few $\mathrm{cm}$ behind the leading edge of melted sludge, the melted sludge depth increases with the distance d from its leading edge and the temperature at a certain depth in the melted sludge increases with d. The temperature distribution in this region is very similar to that examined previously in the case of the flame spread over a thick layer of crude oil siudge[1].

\section{DISCUSSION}

Controlling Mechanisms of Flame Spread

The mode of flame spread is found to change within several minutes after the start of flame spread[Fig. 3, 5 and 6]. This transition has never 


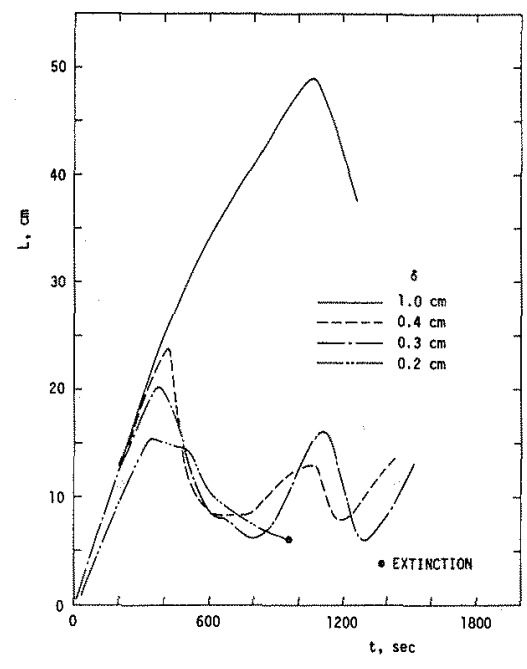

FIGURE 9. Variation of the longitudinal flame size with time; $\mathrm{T}_{\mathrm{i}}=20^{\circ} \mathrm{C}$.

been observed in the studies on flame spread over single component liquid or solid combustibles in a quiescent atmosphere[3-9]. In the first stage, the flame spread rate is almost constant and the flame size continues to increase. On the other hand, in the second stage, the flame spread rate as well as the flame size becomes to fluctuate [Figs. 3, 7 and 9].

In our previous study, the mechanisms of flame spread over a thick sludge layer were discussed [1]. In the discussion, the flame: spread rate was inferred to depend on the gas phase volatile concentration at the sludge surface near the leading flame edge. Since the gas phase volatile concentration depends on the sludge surface temperature, the flame spread rate must be controlled by heat transfer to the sludge surface. The experimental results of our previous study indicate that the dominant mode of heat transfer for flame spread over crude oil sludge is conduction through not-yet-liquefied sludge near the leading flame edge. This implies that the flame spread rate depends on the temperature distribution near the leading flame edge.

A marked difference was observed to exist between the levels of melted sludge surfaces behind the leading flame edges at the first and second stages. In the first stage, the surface of melted sludge is a little higher than that of not-yet-liquefied sludge, while in the second stage, it becomes a little lower. The location of the leading flame edge would depend on the aspect of the melting boundary, and the sludge melts due to heat transfer from the

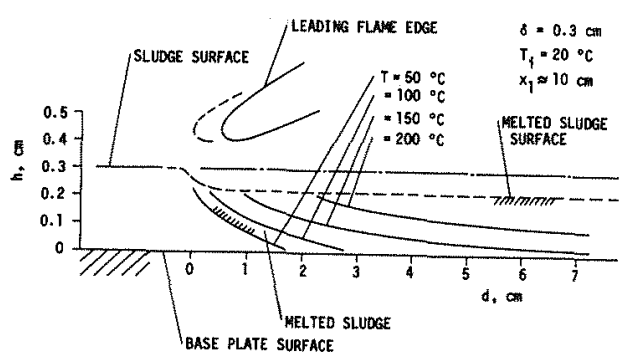

FIGURE 10. Temperature distribution in a sludge layer. leading flame edge. Thus, temperature distribution in the not-yet-liquefied sludge in front of the melting boundary, must be closely related to the height of melted sludge surface.

It can be easily understood from the location of the leading flame edge that the rate of heat transfer to the surface of notyet-liquefied sludge at the 
first stage is much larger than that at the second stage. Consequently, $V_{1}$ is larger than $\mathrm{V}_{2}[\mathrm{Fig} \cdot 9]$.

In the second stage, fluctuation of the flame spread rate was observed (Figs. 3, 5, 6 and 7). If the above discussion is reasonable, this fluctuation of the flame spread rate must be interpreted in a similar manner.

When the ejecting rate of flammable gas from the melted sludge surface becomes small and the flammable gas concentration over the surface decreases to be unable for sustaining a flame in the gas phase, no flame can appear. The trailing flame edge must be at the position where the rate of flammable gas ejection becomes insufficient for sustaining a flame in the gas phase. Thus, the trailing flame edge movement is closely related to the reduction of the height of melted sludge surface which would be caused by the evaporation of melted sludge. For a larger or smaller flame, the consumption of melted siudge occurs in a larger or smaller melted sludge pool area beneath the flame, respectively. At a moment when material vaporizable under the influence of quenching of the base plate is consumed up at the trailing flame edge, the trailing flame edge starts to move to forward. At this moment the height of melted sludge surface is lowest and the spread rate of the leading flame edge must be lowest. Consequently, the trailing flame edge approaches to the leading flame edge, so that the burning area decreases, and the pool area of melted sludge decreases. However, the rate of the melted sludge supply at the leading flame edge does not decrease instantly because it depends on the heat transfer from the leading flame edge. Thus, the height increases again and flame spread rate increases. This inferred behavior is consistent with the results shown in Figs. 5 and 6 . Thus, the flame spread in this case is not inconsistent with that for a thick sludge layer.

Because the dominant mode of heat transfer for flame spread is conduction through the not-yet-liquefied sludge, the quenching effect of the base plate on the flame spread must exist. In a practical case, the structural material of the cargo bay is steel. Its thermal properties are not so much different from that of brass, which is used as the base plate material in the present experiment.

To reveal the effect of the base plate material on flame spread phenomena, the brass plate was replaced by a glass plate. The thermal conductivity of glass is about 1/60 of that of brass. The replacement of the base plate scarcely affected the values of $V_{1}$ and $V_{2}$. However, when the glass base plate was used, the flame behavior at the second stage changed a little, and the fluctuation of the flame spread rate varished.

The thickness of residue behind the trailing flame edge was found to be less than $0.1 \mathrm{~cm}$, Which is small as compared to the value of more than 0.2 cm for the brass plate. This phenomenon is considered to be due to the small heat loss to the glass base plate. These results of flame spread over a crude oil sludge layer on a glass plate indicate that the flame spread mechanisms and dominant mode of heat transfer for flame spread are similar to those on a metal plate. Further, the limiting thicknesses on a glass plate are almost the same as those on a brass plate.

\section{Possible Application of Results for Practical Purposes}

As pointed out throughout the present study, there are two types of Iimiting thicknesses. One is the thickness below which the sludge cannot be ignited, and the other is that below which the spreading flame stopped to 
spread at a few minutes after starting to spread.

At both limiting conditions, the vapor concentration near the leading flame edge must be a limiting value for sustaining gas phase combustion under quenching conditions. At the thickness between these limits, $0.2 \sim$ $0.3 \mathrm{~cm}$, the flammable gas supplied to the gas phase must be sufficient for sustaining a flame just after starting flame spread, while that becomes insufficient after several minutes because of the consumption of the melted sludge.

Knowledge of limiting sludge thickness for flame spread is very important for practical purposes. Based on this knowledge, regulations or standards for washing cargo bays before repair works can be established.

Another phenomenon revealed in the present study and important for practical purposes is the finite flame size. When a flame starts from a point on a thin layer of sludge, the burning area is between the leading and trajling flame edges so that its shape must be annular. This is marked difference from the flame spread over a thick sludge layer. It makes the increasing rate of burning area for a thin sludge layer much smaller than that for a thick sludge layer.

These results can be applied not only for the sludge fire but also for the combustible material layer attached to non-flammable material, such as a carpet on a floor, a paint layer covering a wall, etc.

\section{CONCLUSIONS}

The aspects of flame spread over thin layers of crude oil siudge were examined in detail.

The mode of flame spread was found to change at a moment several minutes after the start of flame spread. At the first stage, the flame spread rate was almost constant and the flame size continued to increase. On the other hand, at the second stage, the flame spread rate as well as the flame size changed periodically. The amplitude of these periodic changes increased as the initial sludge thickness decreased. The flame spread rate at the first stage was about twice as large as the mean value of that at the second stage.

Two different types of the limiting thicknesses for the flame spread were revealed. One was the limiting thickness for the initiation of flame spread, and the other was that for the survival of the flame after the transition from the first stage to the second one.

The mechanisms of flame spread were discussed. It was shown that all these phenomena are interpretable by the mechanisms proposed in our previous study.

These results are inferred to be very useful for practical purposes.

\section{ACKNOWLEDGEMENT}

The authors would like to express their sincere thanks to Messrs. F. Tkeye and $\mathrm{H}$. Terunuma for their help in conducting experiments. 


\section{REFERENCES}

1. Hirano, T., Suzuki, T., Sato, J., and Ohtani, H.:Twentieth Symposium(International) on Combustion, (in press).

2. Ohtani, H., Sato, J., and Hirano, T.:ATAA 23rd Aerospace Sciences Meeting, AIAA-85-0396, 1985.

3. Friedman, R.:Fire Research Abstracts and Reviews, 10, 1(1968).

4. Magee, R. S. and McAlevy, III, R. F.:J. Fire and Flammability, 2, $271(1971)$.

5. Sirignano, W. A.:Combustion Science and Technology, 6, 95(1972).

6. Akita, K.:Fourteenth Symposium(International) on Combustion, p. 1075, The Combustion Institute, Pittsburgh, $\mathrm{Pa}, 1973$.

7. Williams, F. A.:Sixteenth Symposium(International) on Combustion, p. 1281, The Combustion Institute, Pittsburgh, $\mathrm{Pa}, 1976$.

8. GIassman, I. and Dryer, F.:Fire Safety J., 3, 123(1980).

9. Fernandez-Pello, A. C. and Hirano, T.:Combustion Science and Technology, 32, 1(1983). 